\title{
COMPARAÇÃO DOS DISCURSOS DE LIVROS DIDÁTICOS DE FILOSOFIA FRANCESES E BRASILEIROS: UMA INTERFACE ENTRE LÍNGUA E CULTURA
}

Daniela Nienkötter Sardá

\section{RESUMO}

Este artigo tem como tema a comparação dos discursos de livros didáticos de filosofia franceses e brasileiros, no âmbito da análise do discurso. Nosso objetivo é apresentar os resultados da análise de um corpus de livros didáticos de filosofia, enfatizando o modo como uma análise em linguística de discurso comparativa permite a interface entre língua e cultura.

PALAVRAS-CHAVE: Análise do discurso; Linguística de discurso comparativa; Livros didáticos de filosofia.

1

(re)inserção do ensino da filosofia como disciplina obrigatória no conjunto das escolas brasileiras, públicas e privadas, é recente. Presente no país desde 1553, quando da criação da primeira escola secundária pelos jesuítas em Salvador, na Bahia, o ensino da filosofia é marcado por uma história peculiar. Com várias "idas e vindas" ${ }^{1}$ nos programas escolares ao longo do tempo, a filosofia desaparece dos currículos durante a ditadura militar, quando a lei 5.692 substitui o seu ensino pelo de educação moral e cívica. $\mathrm{Na}$ década de 1980, ela retorna aos currículos, mas como disciplina optativa.

1 Para um panorama mais detalhado da história do ensino da filosofia no Brasil, cf. KOHAN (2007, p. 78), em francês. Há, também, uma tradução dessa obra em inglês intitulada Philosophy. A school of freedom. 
Foi nos últimos anos, mais precisamente em 2 de junho de 2008, com a Lei Federal no 11.684/08, que o ensino da filosofia (e o de sociologia) tornou-se obrigatório no Ensino Médio brasileiro.

$\mathrm{Na}$ França, o ensino da filosofia nas escolas também é questionado. Presente nos currículos escolares desde o início do século XIX, com um pequeno eclipse de 1852 a 1863, a filosofia é uma disciplina obrigatória no último ano do Ensino Médio francês - a classe Terminale (SHERRINGHAM, 2006, p. 61). Todavia, recentemente discute-se a respeito da possibilidade de se antecipar seu ensino da classe Terminale para as classes de Seconde (primeiro ano do Ensino Médio na França).

O quadro atual de debate sobre o ensino da filosofia nos dois países justifica nosso interesse em expor os resultados de uma pesquisa, no âmbito da análise do discurso, relativa à comparação de livros didáticos de filosofia franceses e brasileiros. O objetivo do estudo foi investigar qual é a finalidade do ensino da filosofia na França e no Brasil. Como teoria principal que sustentou essa comparação, temos a linguística de discurso comparativa, corrente trabalhada na França com uma atenção privilegiada, conforme veremos a seguir.

Nosso trabalho em linguística de discurso comparativa teve início com uma impressão de diferença entre os livros didáticos franceses e brasileiros de um modo geral. Ao folhearmos e lermos alguns trechos dos livros de filosofia nos dois países, chamou nossa atenção logo de início o quanto os livros franceses pareciam dirigir-se ao exame do baccalauréat ${ }^{2}$. Para a realização desse exame, o aluno deve dominar os gêneros dissertação filosófica e comentário de texto, e os livros didáticos de filosofia franceses nos pareceram frisar a importância de tais competências. Nos livros didáticos brasileiros, por sua vez, a filosofia parecia ser exposta de maneira mais livre, relacionada a temas e assuntos variados, com a intenção, talvez, de sensibilizar o leitor quanto à importância de se ter uma boa cultura geral.

Convencidos da diferença entre os discursos dos livros didáticos franceses e brasileiros e levantando a hipótese de que o ensino da filosofia também deveria, consequentemente, ter objetivos distintos nos dois países, decidimos

2 Baccalauréat: "Grau universitário francês (criado em 1808) conferido após exames que finalizam os estudos secundários" [tradução nossa]. Cf. Dicionário eletrônico Le Grand Robert de la Langue Française (2005). 
comparar os discursos desses livros didáticos tendo a análise do discurso, mais precisamente a linguística de discurso comparativa, como quadro teórico.

Cabe observar que, em uma análise de linguística de discurso comparativa - também conhecida como análise do discurso contrastiva -, "[...] coloca-se em relação não as diferentes línguas, como o faz tradicionalmente a linguística contrastiva, mas as manifestações de um mesmo gênero discursivo [...] em ao menos duas comunidades diferentes" (VON MÜNCHOW, 2011, p. $13)^{3}$. Dessa forma, em nossa pesquisa, analisamos os discursos de um mesmo gênero textual - o gênero livro didático de filosofia - em duas comunidades distintas.

No quadro da linguística de discurso comparativa, inspiramo-nos no modelo de descrição e interpretação desenvolvido por von Münchow (2004, 2011). Esse modelo articula as representaçóes sociais, mentais e discursivas aos módulos linguísticos (enunciativo, semântico e composicional) assim como às marcas linguísticas. Ele é assim esquematizado:

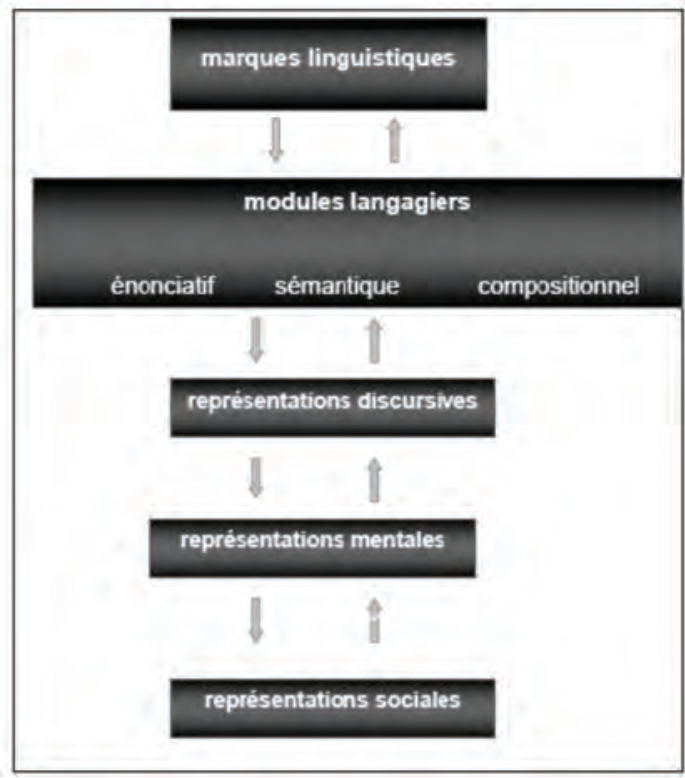

Figura 1: Modelo de descrição e interpretação (In: VON MÜNCHOW, 2011, p. 14).

3 A fim de garantir uma maior legibilidade ao texto, optamos por traduzir as citaçóes em língua estrangeira. Todas as traduçóes presentes neste artigo são de nossa autoria. 
No modelo acima, as marcas linguísticas (marques linguistiques) são “[os] únicos dados 'objetiváveis” (VON MÜNCHOW, 2010). No entanto, como essas marcas são próprias a uma dada língua, é preciso que as articulemos aos módulos linguísticos (modules langagiers), que são próprios à linguagem humana e não a tal ou tal língua em particular (VON MÜNCHOW, 2010). São as marcas linguísticas presentes nos discursos dos autores que nos guiam em direção às representações sociais difundidas na comunidade analisada.

Em nosso presente artigo, mostraremos o exemplo de uma análise feita com base em uma categoria ligada ao módulo enunciativo: a categoria discurso reportado (discours rapporté). Segundo von Münchow (2011, p. 14), uma vez analisadas as marcas linguísticas e estabelecidas algumas hipóteses e "interpretaçôes simples" sobre um dado fenômeno, pode-se, ainda, ligar tais interpretaçôes a determinadas causas - institucionais, históricas etc. É o que nos dispomos a apresentar na última seção deste artigo.

\section{O corpus}

Nosso corpus consistiu em quatro livros didáticos de filosofia contemporâneos, dois franceses (Nouvel abrégé de philosophie e Philosophie, collection $A B C d u B a c$ ) e dois brasileiros (Convite à filosofia e Filosofando: introdução à filosofia).

Para Pekelder (2010, p. 22), "É geralmente admitido que um dos problemas centrais da linguística contrastiva reside no estabelecimento de um tertium comparationis, ou seja, uma base de comparação". Von Münchow e Rakotonoelina (2006), assim como Claudel e Tréguer-Felten (2006), mostram que o gênero discursivo se impóe como escolha de um tertium comparationis pelos autores que trabalham com a comparação de discursos.

Tendo escolhido o gênero livro didático de filosofia como objeto de comparação, restava-nos a tarefa de selecionar exemplares desse gênero de cada país 4 . O critério de escolha dos títulos brasileiros - já que o guia do livro

4 Decidimo-nos por dois livros didáticos de filosofia de cada país em questão porque cada livro tem cerca de duzentas páginas, o que nos daria um bom material para a constituição de um corpus exploratório significativo, assim como de um subcorpus de referência. 
didático de filosofia do Programa Nacional do Livro Didático (PNLD) ainda não havia sido lançado quando coletamos nosso corpus - foi seu grau de adoçáo no Ensino Médio. Para saber quais eram os livros mais utilizados no Brasil, optamos por uma enquete junto a professores de filosofia da rede pública de ensino, que nos asseguraram que Convite à filosofia e Filosofando: introduçáo à filosofia eram os mais adotados. No que tange à escolha do corpus francês, a maioria dos professores questionados na França disse não utilizar livros didáticos em seus cursos. Selecionamos, então, nossos exemplares - Nouvel abrégé de philosophie e Philosophie, collection $A B C d u$ Bac - dentre os livros mais vendidos, segundo enquete feita em uma das livrarias mais populares de Paris no ramo dos livros didáticos.

Começamos a análise do nosso corpus estabelecendo as categorias descritivas mais relevantes. Optamos, assim, pelo estudo de dois módulos linguísticos (Figura 1): o semântico e o enunciativo. Dado o espaço limitado deste artigo, decidimos expor detalhadamente apenas um desses módulos - o enunciativo - com a análise referente ao discurso reportado (discours rapporté), pois cremos que essa categoria nos revelou os resultados mais expressivos.

A seguir, mostraremos como os autores dos livros didáticos de filosofia remetem-se a filósofos e aos seus textos no corpus analisado. Começaremos pela análise dos livros franceses, seguida da análise dos livros brasileiros. Logo após, apresentaremos nossas interpretaçóes causais, resultantes das análises linguísticas anteriores.

\section{Análise das remissões ao filósofo Espinosa em Nouvel Abrégé de Philosophie e Philosophie - Collection ABC du Bac}

A escolha do filósofo Espinosa deve-se ao fato de ele ser citado nos quatro livros analisados. Utilizaremos, na observação das remissóes a Espinosa em nosso corpus, a nomenclatura de Rabatel (2004b), que diferencia L1/E1 (locutor/enunciador primário, ou seja, o autor do livro didático) de 12/e2 (locutor/ enunciador citado, ou seja, Espinosa).

Na obra francesa Nouvel abrégé de philosophie (doravante NAP), notamos a presença de diversas passagens seguidas de discurso direto (DD), nos moldes do exemplo abaixo: 
(1) Il faut différencier, dès l'abord, cette liberté comme autodétermination humaine et autonomie du choix, de la liberté divine : Dieu est absolument libre parce qu'il produit toute perfection sans être contraint par aucune autre chose. Dieu existe, dit Spinoza, par la seule nécessité de sa nature et donc il est seul cause libre. « Dieu seul est cause libre. Car Dieu seul existe par la seule nécessité de sa nature et agit par la seule nécessité de sa nature. Par suite, il est seul cause libre " B. Spinoza, Éthique, Garnier-Flammarion. (NAP, p. 256, grifo nosso).

É preciso diferenciar, desde o início, essa liberdade como autodeterminação humana e autonomia da escolha, da liberdade divina: Deus é absolutamente livre porque ele produz toda a perfeição sem ser coagido por nenhuma outra coisa. Deus existe, diz Espinosa, pela única necessidade de sua natureza e, portanto, somente ele é causa livre. "Somente Deus é causa livre. Pois somente Deus existe pela única necessidade de sua natureza e age pela única necessidade de sua natureza. Consequentemente, ele é a única causa livre”.

De acordo com nossa leitura, em $N A P$, em geral, as citações têm a função de "provar" o que foi dito anteriormente por L1/E1, como se o DD fosse mais "fiel" à ideia do filósofo. Todavia, sabemos que a ideia de o DD ser mais fiel é um tanto inocente: o DD não é nem mais fiel nem mais simples do que o discurso indireto (DI). Essa é uma visão difundida nas gramáticas tradicionais, mas contestada por autores como Authier-Revuz (1992).

Na passagem (1) notamos, ainda, o fenômeno de "apagamento enunciativo" (effacement énonciatif) descrito por Rabatel (2004b). Segundo Charaudeau,

O sujeito falante se apaga do seu ato de enunciação, e não implica o interlocutor. Ele testemunha a maneira com que os discursos do mundo (o terceiro) se lhe impóem. Disso resulta uma enunciaçáo aparentemente objetiva (no sentido de "desvinculada da subjetividade do locutor") que deixa aparecer sobre a cena do ato de comunicaçáo Propósitos e Textos que não pertencem 
ao sujeito falante (ponto de vista externo) (apud RABATEL, 2004a, p. 7).

Isso porque, em (1), notamos uma "desinscrição enunciativa" (désinscription énonciative). Esse fenômeno pode ser marcado de diversas maneiras. Ele pode corresponder

[...] à passagem de uma enunciação pessoal a uma enunciação impessoal, com, em fase intermediária, a presença de formas pessoais ou de séries verbais "dêiticas" [tiroirs verbaux "déictiques"] cuja interpretação não depende (ou não depende mais) de dados situacionais, como quando eu, tu (nós, vós) adquirem um valor genérico. É então frequente que essas formas permutem-se entre elas ou com um -se [on] indefinido ou com a não-pessoa (RABATEL, 2004b, p. 19).

No caso de (1), temos a passagem de uma enunciação pessoal a uma enunciação impessoal, pois, antes desse excerto, o locutor escrevia em nós de modéstia (nous de modestie), da seguinte maneira: "C'est ce concept philosophique de liberté que nous nous efforcerons d'abord de cerner, nous demandant en quoi consiste cette capacité d'autodétermination" (NAP, p. 256, grifo nosso) ["É este conceito filosófico de liberdade que nós nos esforçaremos inicialmente por delimitar, nos perguntando em que consiste esta capacidade de autodeterminação"].

Vários outros exemplos de apagamento enunciativo por desinscrição enunciativa são encontrados nesse livro didático e, consequentemente, no capítulo sobre Espinosa, cada vez que o autor expóe sua interpretação do discurso de um filósofo, seguido de uma citação desse último. De resto, o autor desse livro também emprega bastante nos exemplos o uso do "eu genérico". Quase todos os empregos do eu (je) são genéricos e ligados ao fenômeno de apagamento enunciativo, como mostra o exemplo abaixo:

(2) Le langage n'est pas seulement un moyen de communication. Parler, c'est aussi agir et dominer. Dire, c'est faire, selon l'expression célèbre du philosophe britanique J. L. Austin 
(1911-1960), qui donna ce nom à un de ses ouvrages. Produire certaines énonciations, c'est exécuter une action. Par exemple, quand je dis " oui, je le veux " (je prends cette femme comme épouse légitime), " $\mathbf{j}$ 'ouvre la séance », etc., mes propositions ne constatent pas, mais tendent à accomplir quelque chose. Elles sont performatives : ce sont des énoncés linguistiques ayant pour fonction de faire, et non pas seulement de dire. Parler, c'est agir. "Quand je dis, à la mairie ou à l'autel, etc. "Oui [je le veux]", je ne fais pas le reportage d'un mariage : je me marie ». J. L. Austin, Quand dire, c'est faire, Seuil. (NAP, p. 83, grifo nosso).

A linguagem não é somente um meio de comunicação. Falar é também agir e dominar. Dizer é fazer, segundo a expressão célebre do filósofo britânico J. L. Austin (1911-1960), que deu esse nome a uma de suas obras. Produzir certas enunciaçóes é executar uma ação. Por exemplo, quando eu digo "sim, eu aceito" (eu aceito esta mulher como legítima esposa), "eu declaro aberta a sessão" etc., minhas proposiçôes não constatam, mas tendem a realizar alguma coisa. Elas são performativas: são enunciados linguísticos tendo por função fazer, e não somente dizer. Falar é agir. "Quando eu digo, na prefeitura ou no altar etc., 'Sim [eu aceito]', eu não faço referência a um casamento: eu me caso".

Observando o enunciado (3) abaixo, notamos outro apagamento enunciativo cuja estratégia é a da multiplicação das fontes enunciantes (multiplication des sources énonçantes) (RABATEL, 2004b, p. 21). Veja o exemplo (3):

(3) Spinoza retrouve cette liaison de la liberté et de la raison, mais de manière différente de Descartes : à ses yeux, Dieu est seul véritablement libre (voir $\$ 1$ ). Chez les hommes, la liberté est une illusion. En effet, tout ce qui est est en Dieu et résulte nécessairement de la nature divine. "Les hommes se trompent en ce qu'ils se croient libres; et cette opinion consiste en cela seul qu'ils ont conscience de leurs actions et sont ignorants 
des causes par où ils sont déterminés; ce qui constitue donc leur idée de la liberté, c'est qu'ils ne connaissent aucune cause de leurs actions ». B. Spinoza, Éthique, Garnier-Flammarion. (NAP, p. 257).

Espinosa reencontra esse vínculo da liberdade e da razão, mas de maneira diferente de Descartes: aos olhos de Espinosa, Deus é o único verdadeiramente livre (ver $₫ 1$ ). Entre os homens, a liberdade é uma ilusão. Com efeito, tudo o que existe está em Deus e resulta necessariamente da natureza divina. "Os homens se enganam acreditando-se livres; e essa opiniáo consiste somente no fato de que eles têm consciência de suas açóes e são ignorantes das causas pelas quais eles são determinados; o que constitui, então, sua ideia da liberdade é que eles não conhecem nenhuma causa de suas açóes".

O L1/E1 de NAP cita em (3) as concepçóes de Descartes e Espinosa sobre a liberdade e as faz dialogar; assim, ele fica em posição de superenunciador (surénonciateur) a fim de garantir o apagamento enunciativo. O L1/E1 de $N A P$ é o mediador de uma cultura filosófica, e "[...] por sua aptidão a colocar em perspectiva referências bibliográficas singulares, e mesmo por uma certa desenvoltura no papel de 'agente das atribuiçóes enunciativas', L1/E1 manifesta um ethos 'soberano' que se acomoda bem à postura de superenunciador [...]” (RABATEL, 2004b, p. 23).

Interpretamos, portanto, que toda a riqueza de citações do livro didático em questão, $N A P$, reflete a vontade de seu autor em apagar sua própria enunciação. Segundo Tuomarla (1999, p. 11), "O DD é a forma gramatical que permite ao L [locutor] citante enunciar um conteúdo e não o assumir, atribuindo-o a outro L". Todavia, mesmo se o discurso da citação é atribuído a outro locutor/enunciador - em nossos exemplos, a Espinosa -, a fidelidade a esses discursos deve sempre ser questionada. Mesmo que o L1/E1 de NAP queira manter-se fiel aos discursos dos filósofos, ele não o é de fato, já que, enquanto superenunciador, é ele quem organiza os pontos de vista por intermédio de citaçôes que já foram deslocadas de seu contexto original. 
Mas em NAP há outras estratégias usadas nas remissóes a Espinosa e a seus textos, além das citações. Uma dessas estratégias é a utilização dos discursos interpretados por meio de marcas que diferenciam o discurso citante do discurso citado, utilizadas nas paráfrases. Observaremos o uso dos atributivos (attributifs), a saber "[...] formas como segundo $X$, de acordo com $X$ [selon $X$, d'après $X]$, os incisos, os verbos introdutores seguidos de completiva, os nomes próprios, os sintagmas introdutores, os discursos tornados narrações..." (ROSIER, 2008, p. 50).

Em (1), mais precisamente na passagem abaixo:

Dieu existe, dit Spinoza, par la seule nécessité de sa nature et donc il est seul cause libre. (NAP, p. 256, grifo nosso)

Deus existe, diz Espinosa, pela única necessidade de sua natureza e, portanto, somente ele é causa livre.

O inciso "dit Spinoza" (diz Espinosa) em negrito atribui o discurso de sua esquerda e de sua direita ao 12/e2 (Espinosa). Segundo Rosier (2008, p. 65), o inciso "[...] participa da marcação do discurso citante e [...] permite ou facilita o aparecimento de enunciadores E2 (em DD) ou $e$ (em DI)" (grifo nosso). Esse inciso tem também a função de integrar o DI sobre Espinosa à estrutura textual que o cerca (p. 68).

Em (3), em contrapartida, o L1/E1 compara o discurso de Espinosa com o de Descartes, dizendo que, para o primeiro, "Dieu est seul véritablement libre" ("Deus é o único verdadeiramente livre"). Para tanto, ele utiliza uma forma de modalização em discurso segundo (modalisation en discours second), marcada pelo uso de à ses yeux (aos olhos de X). Trata-se de uma forma que serve para atribuir um dizer a outrem, como selon $X$, d'après $X$, pour $X$, suivant $X$ (segundo $X$, de acordo com $X$, para $X$, seguindo $X$ ); na verdade, à ses yeux é uma variação semântica dessas formas, tais como à l'entendre, à son avis, etc. (ao que parece, em sua opiniâo) (ROSIER, 2008, p. 104). Em suma, ainda segundo Rosier (2008, p. 104), "As modalizaçóes em discurso segundo atribuem um discurso citado a um discurso citante, segundo um grau de literalidade variável, indo do discurso reportado ao discurso interpretado".

Esses atributivos, assim como a modalização em discurso segundo, são também associados à estratégia de superenunciação, pois é o L1/E1 quem 
atribui os dizeres aos outros filósofos, organizando um discurso objetivo, no qual L1/E1 existe enquanto relator do discurso erudito dos filósofos. É preciso, todavia, observar que esta posição de superenunciador não corresponde a uma "modéstia enunciativa"; ao contrário, "[...] essa modéstia [...] pode ser estratégica e [...] valorizar A [L1/E1] do ponto de vista social: pelo seu conhecimento da obra [...]" (ROSIER, 2008, p. 42).

A análise dos fenômenos de apagamento enunciativo e do uso de atributivos no livro didático NAP nos levou à seguinte "interpretação simples":

\section{NAP é um livro que pretende ser objetivo e fiel ao discurso dos filóso- fos. É o texto filosófico que conta, antes de tudo. Ao autor do livro, cabe a tarefa de organizar o pensamento filosófico e de sugerir um modo de estruturação dos diferentes pontos de vista filosóficos sobre um dado tema ou noçáo.}

Organizar o pensamento de diversos filósofos em torno de uma noção apresentada: não é esse, justamente, o procedimento que os estudantes franceses devem seguir no exame do baccalauréat? Discutiremos esse ponto adiante, quando da interpretação causal de nosso corpus.

Quanto ao livro didático Philosophie - collection $A B C$ du Bac (doravante $P$ - $A B C$ ), por sua vez, observamos o mesmo procedimento de apagamento enunciativo presente em $N A P$. Podemos acompanhar esse procedimento principalmente em (4), quando o L1/E1 de $P-A B C$ faz referência à filosofia de Espinosa comparando-a com aquela dos estoicos (assunto do parágrafo anterior), dizendo que Espinosa também "considera a natureza como submetida à necessidade", e, em seguida, acrescenta uma citação do filósofo para provar essa afirmação, que será seguida de formas pessoais genéricas: nesse exemplo, um "nós" genérico, que é reforçado pela ocorrência do substantivo "homem", também empregado de modo genérico:

(4) Comme les stoïciens, Spinoza considère la nature comme soumise à la nécessité. "Dans la nature, il n'existe rien de contingent, écrit-il dans l'Éthique (1677); mais tout est déterminé par la nécessité de la nature divine à exister et à agir selon une modalité particulière ». Ce que nous appelons 
la " liberté » ne serait donc rien d'autre que notre ignorance des causes véritables qui nous déterminent. Car l'homme est d'abord esclave : soumis aux erreurs des sens et aux illusions de la passion, il s'agite de tous côtés, voyant quelquefois le meilleur, faisant souvent le pire. ( $P-A B C$, p. 219, grifo nosso)

Como os estoicos, Espinosa considera a natureza como submetida à necessidade. "Na natureza, não existe nada de contingente, escreve ele na Ética (1677); mas tudo é determinado pela necessidade da natureza divina de existir e agir segundo uma modalidade particular". O que nós chamamos "liberdade" não seria outra coisa senão nossa ignorância das verdadeiras causas que nos determinam. Pois o homem é antes de tudo escravo: submetido aos erros dos sentidos e às ilusôes da paixão, ele se agita para todos os lados, vendo às vezes o melhor, fazendo frequentemente o pior.

Essa passagem é seguida de outra que também contém uma "série de dêiticos" (tiroirs déictiques). Além disso, em $P$ - $A B C$ também observamos o fenômeno de apagamento enunciativo, quando L1/E1 multiplica as fontes enunciadoras para ficar em posição de superenunciador, ou seja, no papel de mediador de "discursos outros". Isso pode ser observado em (4), quando da comparação de Espinosa com os estoicos, a fim de reagrupar diversas visóes sobre um mesmo tema.

No intuito de provar o que afirma, o autor (ou L1/E1) de $P$ - $A B C$ serve-se de citaçóes em várias passagens do livro, como no exemplo (5), em que temos um DD introduzido por um que:

(5) On pense, écrit Spinoza dans son Traité théologico-politique (1670), que « l'esclave est celui qui agit par commandement, et l'homme libre celui qui agit selon son bon plaisir. Cela cependant n'est pas absolument vrai, car en réalité, être captif de son plaisir [...] c'est le pire esclavage ». $(P-A B C$, p. 218, grifo nosso). 
Pensa-se, escreve Espinosa em seu Tratado teológico-politico (1960), que “o escravo é aquele que age por comando, e o homem livre, aquele que age segundo seu bel-prazer. Isso, no entanto, não é absolutamente verdadeiro, pois, em verdade, ser cativo de seu prazer [...] é a pior escravidáo”.

Temos, assim, em $P-A B C$, citaçóes que seguem o exemplo de $N A P$, nas quais o DD aparece depois de um discurso interpretado por L1/E1. Todavia, o L1/E1 de $P$ - $A B C$ utiliza outras estratégias para inserir citaçóes, como as citaçóes introduzidas por um que - exemplo (5) -, ou fragmentos de citação que são inseridos no interior de um discurso interpretado, como em (6), quando o L1/E1 de $P-A B C$ nos fala de Descartes:

(6) Cette liberté, qu'on appelle la « liberté d'indifférence », est tenue par Descartes comme «le plus bas degré de la liberté ». Elle s'exerce toujours, en effet, à l'occasion de choix insignifiants [...] (P-ABC, p. 219, grifo nosso).

Essa liberdade, que se chama a "liberdade de indiferença", é tida por Descartes como “o mais baixo grau da liberdade”. Ela se exerce sempre, com efeito, na ocasião de escolhas insignificantes [...].

Constatamos também que não são todos os discursos interpretados em $P-A B C$ que são seguidos de uma citação, como era o caso em $N A P$. De tempos em tempos, o L1/E1 de $P$ - $A B C$ nos apresenta uma interpretação inspirada em um filósofo, mas cuja fonte ele não menciona. É o caso do exemplo (7), no qual constatamos a presença de um discurso chomskiano, mesmo que o autor não mencione em momento algum o nome do linguista:

(7) Seul l'homme peut à tout moment composer des phrases nouvelles et comprendre des discours qu'il n'a jamais entendus auparavant. ( $P-A B C$, p. 113).

Somente o homem pode a todo momento compor frases novas e compreender discursos que ele nunca ouviu antes. 
Por fim, constatamos, também em $P-A B C$, a presença de atributivos, que introduzem discursos interpretados e discursos reportados. Visto que se tratam dos mesmos atributivos observados em $N A P$, não acrescentaremos aqui novos exemplos.

A análise dos discursos de $P-A B C$ nos orienta em direção à interpretação simples a seguir:

$\mathrm{P}-\mathrm{ABC}$ é um livro didático que visa sobretudo a articular os discursos dos filósofos abordados. É o texto filosófico que conta, já que o livro contém um número considerável de citaçóes, mas é a articulação desses discursos o ponto mais importante (tendo em vista a quantidade significativa de discursos interpretados, articulados por uma multiplicaçáo das fontes enunciantes).

\section{Análise das remissões ao filósofo Espinosa em Convite à Filosofia e Filosofando: introdução à Filosofia}

Em Convite à Filosofia (doravante CF), Espinosa é mencionado no capítulo $A$ liberdade. Três concepçóes de liberdade nos são apresentadas: 1) as concepçóes de Aristóteles e de Sartre; 2) a concepção que unifica necessidade e liberdade e 3) a concepção de liberdade como possibilidade objetiva (que reúne elementos das duas concepçóes anteriores). Espinosa é abordado quando da discussão da segunda concepção, aquela que unifica necessidade e liberdade.

Nossa primeira observação quanto à maneira que o L1/E1 de $C F$ refere-se a Espinosa e a seus dizeres é a ausência de citaçóes. Há em $C F$ uma forte presença de discursos interpretados sobre a filosofia de Espinosa, introduzidos por atributivos, a exemplo de Como explica X, Para X, diz X, Espinosa [...], diz ele, todos seguidos de um discurso interpretado pelo L1/E1 de CF. Vemos, então, que o L1/E1 de CF comporta-se como um superenunciador (RABATEL, 2004a, p. 21) que organiza pontos de vista diversos sobre um mesmo tema. Todavia, esse não é o caso em todo o capítulo.

No capítulo em questão, são mencionados três poetas: José Paulo Paes, Carlos Drummond de Andrade e Vicente de Carvalho. Um poema de cada um deles será ligado a uma das concepçóes de liberdade apresentadas no início do capítulo. Segundo o L1/E1 de CF, os três poetas nos colocam, mediante 
seus poemas, em face da liberdade enquanto problema ( $C F$, p. 332). O poema de José Paulo Paes fala de "torneira seca, luz apagada e porta fechada", o de Drummond fala de um "vasto mundo" e o último, de Vicente de Carvalho, fala de uma "árvore milagrosa”. Esses três temas poéticos serão articulados com as concepçóes de liberdade.

Dito isso, o L1/E1 de $C F$ primeiramente tece consideraçóes sobre as visóes do poeta para, em seguida, falar das três grandes concepções filosóficas de liberdade. Nessa parte, o L1/E1 de CF comportar-se-á como um superenunciador, pois atribuirá os dizeres aos filósofos organizando um discurso objetivo no qual Aristóteles e Sartre dizem tais e tais coisas, mesmo que suas visóes respectivas sobre a liberdade possam ser reagrupadas. Em seguida, a concepção espinosista, no que ela tem de parecida com a hegeliana e a estoicista por unificar necessidade e liberdade, torna possível, na opiniāo do L1/E1 de $C F$, o reagrupamento dos estoicos, de Hegel e Espinosa sob uma mesma categoria comum (CF, p. 334). Enfim, uma terceira concepção introduz a noção de possibilidade objetiva, a qual será encontrada em pensadores marxistas e fenomenólogos e existencialistas ( $C F$, p. 336).

No entanto, antes de articular a poesia com as três concepçóes de liberdade, o L1/E1 de CF apresenta alguns exemplos sobre a necessidade oposta à liberdade, escritos em primeira pessoa genérica (8), e outros sobre a contingência oposta à liberdade, escritos igualmente em primeira pessoa genérica (9). Após o exame desses dois exemplos, uma conclusão sobre os dois casos nos é apresentada (10), dessa vez valendo-se da terceira pessoa genérica:

(8) Não escolhi nascer numa determinada época, num determinado país, numa determinada família, com um corpo determinado. As condiçóes de meu nascimento e de minha vida fazem de mim aquilo que sou, e minhas ações, meus desejos, meus sentimentos, minhas intençôes, minhas condutas resultam dessas condiçóes, nada restando a mim senão obedecê-las. Como dizer que sou livre e responsável? Se, por exemplo, nasci negra, mulher, numa família pobre, numa sociedade racista, machista e classista, que me discrimina racial, sexual e socialmente, que me impede o acesso a um trabalho bem remunerado, que me proíbe a entrada em certos lugares, 
que me interdita amar quem não for da mesma "raça" e classe social, como dizer que sou livre para viver, sentir, pensar e agir de uma maneira que náo escolhi, mas me foi imposta? $(C F, \mathrm{p}$. 333, grifo nosso).

(9) Quando minha mãe estava grávida de mim, houve um acidente sanitário, provocando uma epidemia. Minha mãe adoeceu. Nasci com problemas de visão. Foi por acaso que a gravidez da minha mãe coincidiu com o acaso da epidemia: por acaso, ela adoeceu; por acaso, nasci com distúrbios visuais. Tendo tais distúrbios, preciso de cuidados médicos especiais. No entanto, na época em que nasci, o governo do meu país instituiu um plano econômico de redução de empregos e privatização do serviço público de saúde. Meu pai e minha mãe ficaram desempregados e não podiam contar com o serviço de saúde para meu tratamento. Tivesse eu nascido em outra ocasiáo, talvez pudesse ter sido curada de meus problemas visuais. Quis o acaso que eu nascesse numa época funesta. Tal como sou, há coisas que não posso fazer. Sou, porém, bem dotada para a música e poderia receber uma educação musical. Porém, houve a decisão do governo municipal de minha cidade de demolir o conservatório musical público. Não posso pagar um conservatório particular e ficarei sem a educaçáo musical, porque, por acaso, moro numa cidade que deixará de ter um serviço público de educação artística. Morasse eu em outra cidade ou fosse outro o governo municipal, isso não aconteceria comigo. Como, entáo, dizer que sou livre para decidir e escolher, se vivo num mundo onde tudo acontece por acaso? ( $C F$, p. 333, grifo nosso).

(10) Nos dois casos, podemos indagar se, afinal, para nós resta somente "a pena de viver, mais nada" ou se, como escreveu o filósofo Sartre, o que importa não é saber o que fizeram de nós e sim o que fazemos com o que quiseram fazer conosco. ( $C F$, p. 333, grifo nosso). 
Há, ainda, outras passagens em $C F$ nas quais o L1/E1 parece mostrar-se mais, como em (11):

(11) O possível não é o provável. Este é o previsível, isto é, algo que podemos calcular e antever, porque é uma probabilidade contida nos fatos e nos dados que analisamos. O possível, porém, é aquilo criado pela nossa própria ação. É o que vem à existência graças ao nosso agir. No entanto, não surge como "árvore milagrosa" e sim como aquilo que as circunstâncias abriram para a nossa ação. A liberdade é a consciência simultânea das circunstâncias existentes e das açóes que, suscitadas por tais circunstâncias, nos permitem ultrapassá-las, dando-lhes outro rumo e um novo sentido, que não teriam sem a nossa ação [...] Deixado a si mesmo, o campo do presente seguirá um curso que não depende de nós e seremos submetidos passivamente a ele - a torneira permanecerá seca ou vazará, inundando a casa, a luz permanecerá apagada ou haverá um curto-circuito, incendiando a casa, a porta permanecerá fechada ou será arrombada, deixando a casa ser invadida. A liberdade, porém, não se encontra na ilusão do "posso tudo" nem no conformismo do "nada posso". Encontra-se na disposiçáo para interpretar e decifrar as linhas de força $\mathrm{e}$ direçóes do campo presente como possibilidades objetivas, isto é, como abertura de novas direçóes e de novos sentidos a partir do que está dado. ( $C F$, p. 336-337, grifo nosso).

Na passagem acima, não encontramos um apagamento enunciativo; ao contrário, o L1/E1 de $C F$ parece posicionar-se mostrando que a liberdade não se encontra nem na ideia do "eu posso tudo" nem no conformismo do "nada posso".

A análise de todo o capítulo sobre a liberdade nos mostra que, no livro didático em questão, a maneira de se reportar aos discursos de Espinosa não é prototípica do restante do capítulo. Se a parte em que há remissão ao discurso do filósofo holandês é marcada pelo emprego de um discurso interpretado e pelo apagamento enunciativo - dado que o L1/E1 de CF comporta-se como 
um superenunciador -, o mesmo não se pode dizer das outras passagens do capítulo.

O emprego do DD também se faz bastante presente em $C F$, como mostram as passagens abaixo (exemplos não exaustivos):

(12) Essa mesma concepção da liberdade como possibilidade objetiva inscrita no mundo encontramos no filósofo MerleauPonty, quando escreve: "Nascer é [...]". (CF, p. 338).

(13) Num de seus ensaios, Filosofar é aprender a morrer, Montaigne escreve: "Qualquer que seja [...]" (CF, p. 339).

(14) No ensaio O filósofo e sua sombra, Merleau-Ponty nos diz: "De 'morre-se só' para 'vive-se só' a consequência [...]" ( $C F, \mathrm{p}$. 340).

Mediante o que foi exposto até aqui sobre a maneira de se referir a filósofos em $C F$, podemos nos dirigir a uma interpretação simples sobre o discurso desse livro didático:

CF é um livro estruturado de modo a dar conta de um duplo objetivo: 1) apresentar as concepçóes de vários filósofos sobre um determinado tema (a liberdade, por exemplo) e 2) ilustrar essas concepçóes filosóficas (vimos que isso foi feito invocando-se exemplos de necessidade e contingência, ou recorrendo-se a poemas, no caso do capítulo sobre a liberdade aqui analisado). Assim, nos trechos em que o L1/E1 de CF expóe os filósofos/filosofias, observa-se uma neutralidade, ao passo que ele se revela mais quando ilustra um determinado tema.

Em Filosofando: introdução à filosofia (doravante FIF), por sua vez, Espinosa é mencionado no capítulo Podemos ser livres?, mais precisamente no subcapítulo intitulado Os teóricos da liberdade.

Notamos, em FIF, a presença de várias citaçóes, as quais frequentemente são seguidas de uma nota de rodapé com a indicação completa da fonte: autor, obra, editora, página. Alguns exemplos: 
(15) É ainda Hannah Arendt quem diz: “... sempre que o mundo [...]” (FIF, p. 236) .

(16) Assim diz o psicólogo norte-americano John B. Watson (1878-1938): "Deem-me doze crianças sadias [...]" (FIF, p. 238).

(17) Essas relaçôes são de ambiguidade e sobreposição: "A verdade não 'habita' apenas o 'homem interior' [...]" (FIF, p. 241).

O L1/E1 de FIF refere-se a Espinosa intercalando discursos reportados diretos com discursos interpretados, o que corresponde bem ao modo de remeter a outros filósofos nesse livro didático. Além disso, as fontes também são mencionadas por atributivos: nomes próprios (Espinosa [...]), formas como para x (Para Espinosa) etc.

Não encontramos nesse corpus estratégias de apagamento enunciativo flagrantes. O L1/E1 desse livro didático nos apresenta essencialmente um filósofo/texto filosófico por vez. O fenômeno de superenunciação também é ausente. Eis uma passagem de transição de um filósofo a outro, escrita em um estilo bastante didático:

(18) Vejamos algumas concepçôes de filósofos que fizeram uma indagação radical a respeito do que é liberdade, para saber se somos sujeitos livres ou se apenas temos a ilusão da liberdade. (FIF, p. 236).

Essa passagem é seguida de uma explicação sobre a liberdade para os gregos, para Santo Agostinho e na Idade Moderna:

(19) A concepção do livre-arbítrio ainda hoje tem seus adeptos. Vejamos a seguir uma tendência que a ela se opóe de modo radical, para depois analisar aquelas que visam a superar essa contradição. (FIF, p. 237). 
O L1/E1 de FIF escreve, então, sobre o determinismo e o positivismo em ciências humanas. Em seguida, fala de Espinosa e, depois, introduz a fenomenologia e o existencialismo, com Merleau-Ponty e Sartre, respectivamente. Cada trecho de um filósofo a outro é articulado por um discurso de transição: "nós vimos isso, agora veremos aquilo" etc. Durante essas exposições, o L1/ E1 de FIF contextualiza, com ilustraçóes e exemplos, o conteúdo exposto: seja nos contando a tragédia de Édipo, de Sófocles, ou acrescentando quadros ilustrativos intitulados Para saber mais, Quem é? (que apresenta a biografia de um filósofo ou autor), Para refletir (que faz perguntas para o leitor) etc.

A análise desse corpus nos orienta para a seguinte "interpretação simples" acerca do discurso de FIF:

\section{FIF é um livro que expóe os filósofos e suas respectivas filosofias ilus- trando-as sempre com variados exemplos heterogêneos que possam ajudar o leitor a interpretar o que foi apresentado.}

Interpretação causal a partir da análise das remissóes ao filósofo Espinosa nos livros didáticos franceses e brasileiros

A análise dos discursos dos livros didáticos $N A P$ e $P-A B C$ mostrou que, nos livros franceses, é dada uma ênfase ao texto filosófico, cabendo ao autor organizar tais textos, geralmente em torno de um dado tema ${ }^{5}$, e sugerir aos leitores/alunos, por meio da própria estruturação exposta no livro didático, ideias de como articular diferentes pontos de vista filosóficos: tarefa que o aluno francês terá de executar no dia do exame do baccalauréat ${ }^{6}$.

5 Cabe observar que tanto a França quanto o Brasil seguem uma mesma abordagem didática no que concerne ao estudo escolar da filosofia: a abordagem temática (em oposição à abordagem histórica). Assim como o próprio nome já o indica, os livros didáticos franceses e brasileiros são organizados por temas (a liberdade, a linguagem, a felicidade, a moral etc.) e não por períodos da história da filosofia.

6 O exame do baccalauréat é dividido em três séries: "S" (científica), "ES" (econômica e social) e "L" (literária). Os alunos que optam pela série literária têm um número maior de aulas de filosofia durante a classe terminale do que aqueles da série científica. No exame de 2012, por exemplo, os alunos da série $S$ receberam dois assuntos de dissertação, a saber: 1) Temos o dever de buscar a verdade? E 2) Seríamos mais livres sem o Estado?, assim como uma sugestâo de comentário de texto: um trecho de Emílio, de Rousseau. Cf. http://baccalaureat.blog. lemonde.fr/2012/06/18/bac-philo-2012-corrige-des-epreuves/, 26/09/2012. 
A análise de $C F$ e $F I F$ mostrou que o texto filosófico também tem grande importância nos livros didáticos brasileiros. Há nestes uma riqueza de citaçóes e de discursos interpretados com a atribuição da fonte. A mesma importância é dada à ilustração desses textos, com exemplos os mais variados.

A análise de textos institucionais e de dados históricos nos ajuda a explicar as constataçóes feitas. Primeiramente, cabe observar que os livros didáticos são redigidos segundo as instruçôes de um documento oficial - o programa de filosofia do Ministério da Educação francês ou os Parâmetros Curriculares Nacionais (PCN) do Ministério da Educação brasileiro. O programa de filosofia do Ministério da Educação francês parece preocupar-se com o desenvolvimento pessoal dos estudantes, já que nos é dito que "O ensino da filosofia em classes terminais [terminales] tem por objetivo favorecer o acesso de cada aluno ao exercício refletido do juízo, e de lhe oferecer uma cultura filosófica inicial" (MINISTÈRE DE L'ÉDUCATION NATIONALE, 2007, p. 5). O ensino, prossegue o documento, «[...] visa no conjunto dos seus procedimentos a desenvolver nos alunos a aptidáo para a análise, o gosto das noçôes exatas e o sentido da responsabilidade intelectual" (p. 6). No entanto, esse programa também estabelece o conteúdo que deve ser ensinado na classe Terminale, apresentando um grupo de temas que devem ser abordados em sala de aula pelo professor. Tais temas não são optativos no programa francês: cabe ao professor (e ao autor dos livros didáticos) apresentar e trabalhar todos os temas com os alunos. Esses mesmos temas podem vir a ser cobrados no exame do baccalauréat, por conseguinte, o aluno deve, em tese, estar preparado para dissertar ou comentar todos eles. Além disso, o programa do Ministério da Educação francês orienta para o fato de que o professor deve favorecer a capacidade de associação entre filósofos e texto filosófico, o que se reflete no texto dos livros didáticos e explica os fenômenos de superenunciação observados:

A escolha de um número restrito de noções não tem outro princípio senão o de identificar as mais comuns e as mais partilhadas. As noçóes retidas devem constituir um conjunto suficientemente coerente e homogêneo para que seu tratamento faça sempre ressaltar seus vínculos orgânicos de dependência e de associação. [ ] A ordem na qual as noçôes são abordadas e sua articulaçáo com o estudo das obras dependem da liberdade 
filosófica e da responsabilidade do professor, desde que todas as noçóes sejam examinadas. $O$ professor evidenciará a complementaridade dos tratamentos de que uma mesma noção terá podido ser o objeto em momentos distintos de seu ensino (MINISTĖRE DE L'ÉDUCATION NATIONALE, 2007, p. 6, grifo nosso).

Em suma: a observação desse programa ajuda a explicar, em nosso entendimento, a forte presença do texto filosófico nos livros didáticos franceses, assim como o fenômeno de apagamento enunciativo. Além disso, o fato de esse conteúdo vir a ser cobrado no baccalauréat só reforça a necessidade dos livros didáticos franceses de se adequarem ao programa.

Os Parâmetros Curriculares Nacionais do Ministério da Educação brasileiro analisamos aqui o PCN (BRASIL, 2000) e o PCN+ (BRASIL, 2002) de ciências humanas -, por sua vez, apenas sugerem os temas que devem ser trabalhados pelo professor:

Lembramos o que já foi dito na apresentação geral deste documento: "As sugestôes temáticas que serão apresentadas [ ] não devem ser entendidas como listas de tópicos que possam ser tomados por um currículo mínimo, porque é simplesmente uma proposta, nem obrigatória nem única, de uma visão ampla do trabalho em cada disciplina" (BRASIL, 2002, p. 52).

Os livros brasileiros são redigidos de forma a contemplar todas essas sugestóes do Ministério da Educação; depois, caberá ao professor selecionar os conteúdos a serem trabalhados.

A leitura do PCN e do $\mathrm{PCN}+$ parece confirmar a nossa impressão inicial, segundo a qual os livros didáticos brasileiros teriam um discurso mais "livre" e voltado ao desenvolvimento de uma cultura geral nos alunos. O programa brasileiro PCN+ chega a dizer que

[ ] não existe uma Filosofia - como há uma Física ou uma Química -, o que existem são filosofias, podendo o professor (a quem chamaríamos de filósofo-educador) privilegiar certas 
linhas de pensamento e de metodologia, sejam elas a dialética, a fenomenológica, a racionalista etc (BRASIL, 2002, p. 41-42).

Pensamos, ainda, que essa maior liberdade nos livros didáticos brasileiros pode se explicar por um fato histórico particular: a ditadura militar. Tendo em vista que o ensino da filosofia foi suprimido das escolas naquele período, nada mais natural, em nossa opinião, que ele volte com essa proposta de maior liberdade. Segundo nossa interpretação, o retorno do ensino da filosofia no Brasil visa à formação de um cidadão crítico, já que a filosofia é tida como uma disciplina que favorece o exercício da reflexão, proibido na época da ditadura militar no Brasil (1964-1985).

Além disso, os Parâmetros Curriculares Nacionais do Ministério da Educação brasileiro também sugerem que os conteúdos trabalhados no Ensino Médio devem ser contextualizados. Esse documento fala das competências e habilidades que devem ser desenvolvidas nas classes de filosofia, como "Contextualizar conhecimentos filosóficos, tanto no plano de sua origem específica, quanto em outros planos: o pessoal-biográfico; o entorno sócio-político, histórico e cultural; o horizonte da sociedade científico-tecnológica” (BRASIL, 2000, p. 64). Isso ajuda a explicar a necessidade, nos livros didáticos brasileiros, de se ilustrar os conteúdos trabalhados, conforme observamos em nosso estudo.

Essas interpretaçóes causais aqui expostas não são exaustivas, mas ajudam a explicar as interpretaçóes simples feitas a partir da análise das marcas linguísticas observadas em nosso corpus. Confirmamos nossa hipótese de que o ensino da filosofia teria objetivos diferentes na França e no Brasil, corroborando as impressóes que tivéramos ao folhear alguns livros didáticos nos dois países.

\section{Referências}

AUTHIER-REVUZ, Jacqueline. Repères dans le champ du discours rapporté (partie I). L'information grammaticale, 55: 38-42, Paris, 1992.

BRASIL, Secretaria de Educação Média e Tecnológica. Parâmetros Curriculares Nacionais para o Ensino Médio. Parte IV Ciências Humanas e suas Tecnologias. Brasília: Ministério da Educação/Secretaria de Educação Média e Tecnológica, 2000, http://portal.mec.gov.br/seb/arquivos/pdf/cienciah.pdf, 23/05/2011. 
BRASIL, Secretaria de Educação Média e Tecnológica. PCN+ Ensino Médio: Orientaçóes Educacionais Complementares aos Parâmetros Curriculares Nacionais. Ciências Humanas e suas Tecnologias. Brasília: Ministério da Educação/Secretaria de Educaçâo Média e Tecnológica, 2002, http://portal.mec.gov.br/index. php?id=12598:publicacoes\&option=com_content\&view=article, 23/05/2011.

CLAUDEL, Chantal; TRÉGUER-FELTEN, Geneviève. Rendre compte d'analyses comparatives sur des corpus issus de langues/cultures éloignées. Les carnets du CEDISCOR, no 9, 2006, http://cediscor.revues.org/121, 23/05/2011.

DICIONÁRIO ELETRÔNICO LE GRAND ROBERT DE LA LANGUE FRANÇAISE. Paris: Le Robert, 2005.

KOHAN, Walter Omar. La philosophie au Brésil au fil du temps. La philosophie. Une école de la liberté. Paris: Unesco, 2007.

MINISTÈRE DE L'ÉDUCATION NATIONALE, DE L'ENSEIGNEMENT SUPÉRIEUR ET DE LA RECHERCHE. Direction générale de l'enseignement scolaire. Programme Philosophie - classe terminale, série générales et technologiques, Paris, Centre national de documentation pédagogique, 2007 (Collection textes de référence).

PEKELDER, Jan. Le tertium comparationis en linguistique contrastive: problèmes et méthodes. Linguistica Pragensia, 1: 22-36, Varsóvia, 2010.

RABATEL, Alain. L'effacement énonciatif dans les discours rapportés et ses effets pragmatiques. Langages, 156: 03-17, Paris, 2004 a.

Stratégies d'effacement énonciatif et posture de surénonciation dans le Dictionnaire philosophique de Compte-Sponville. Langages, 156: 18-32, Paris, 2004b.

ROSIER, Laurence. Le discours rapporté en français. Paris: Ophrys, 2008.

SHERRINGHAM, Mark. L'enseignement scolaire de la philosophie en France. La revue de l'inspection générale, no 3, 2006, http://media.education. gouv.fr/file/38/6/3386.pdf, 31/08/2012.

TUOMARLA, Ulla. La citation mode d'emploi. Sur le fonctionnement discursif du discours rapporté direct. Helsinski: Academia Scientiarium Fennica, 1999.

VON MÜNCHOW, Patricia. Les journaux télévisés en France et en Allemagne. Plaisir de voir ou devoir de sinformer. Paris: Presses Sorbonne-Nouvelle, 2004. 
. Langue, discours, culture:quelle articulation? (1ère partie). Signes, discours et sociétés, no 4, 2010, http://www.revue-signes.info/document. php?id=1439, 11/09/2012.

. Lorsque l'enfant paraît... Le discours des guides parentaux en France et en Allemagne. Toulouse: Presses Universitaires du Mirail, 2011.

; RAKOTONOELINA, Florimond. Avant-propos. Les carnets du CEDISCOR, no 9, 2006, http://cediscor.revues.org/106, 23/05/2011.

\section{Corpus}

ARANHA, Maria Lúcia de Arruda; MARTINS, Maria Helena Pires. Filosofando: introduçâo à filosofia. São Paulo: Moderna, 2009.

CARDIN, Michel; HUISMAN, Denis; VERGEZ, André. Philosophie. Paris: Nathan. Collection ABC du Bac, 2007.

CHAUI, Marilena. Convite à filosofia. São Paulo: Ática, 2009.

RUSS, Jacqueline; FARAGO, France. Nouvel abrégé de philosophie. Paris: Armand Colin, 2010.

\section{COMPARAISON DES DISCOURS DE MANUELS SCOLAIRES DE PHILOSOPHIE FRANÇAIS ET BRÉSILIENS : UNE INTERFACE ENTRE LANGUE ET CULTURE}

\section{RÉSUMÉ}

Cet article a pour thème la comparaison des discours de manuels scolaires de philosophie français et brésiliens, dans le cadre de l'analyse du discours. Notre but c'est de présenter les résultats de l'analyse d'un corpus de manuels scolaires de philosophie en montrant comment une analyse en linguistique de discours comparative permet l'interface entre langue et culture.

MOTS-CLÉ: Analyse du discours ; Linguistique de discours comparative; Manuels scolaires de philosophie.

Recebido em: 30/08/2013 